\title{
Nonlinear absolute sea-level patterns in the long-term-trend tide gauges of the East Coast of North America
}

https://doi.org/10.1515/nleng-2021-0001

Received Feb 26, 2019; accepted Jun 9, 2020.

\begin{abstract}
The paper provides an estimate of the latest relative and absolute rates of rise and accelerations of the sea levels for the East Coast of North America. The computation is based on the long-term trend (LTT) tide gauge records of the relative sea levels and the Global Navigation Satellite System (GNSS) time series of the absolute position of fixed dome nearby the tide gauges. The GNSS result is used to infer the subsidence or uplift of the tide gauge instrument. The data of 33 LTT tide stations with more than 80 years of data are shown. The average relative sea-level rise is $+2.22 \mathrm{~mm} / \mathrm{yr}$. subjected to a small, positive average acceleration of $+0.0027 \mathrm{~mm} / \mathrm{yr}^{2}$. The average absolute velocity of the tide gauge instruments is $-0.52 \mathrm{~mm} / \mathrm{yr}$. translating in an average absolute sea-level rise of $+1.70 \mathrm{~mm} / \mathrm{yr}$. This is the first paper publishing a comprehensive survey of the absolute sea-level rates of rise along the East Coast of North America using the reliable information of relative sea-level rates of rise from LTT tide gauges, plus the absolute subsidence rates from GNSS antennas that are close to the tide gauges installations.
\end{abstract}

Keywords: tide gauges, GNSS, sea levels, subsidence

\section{Introduction}

The absolute sea-level rise is computed by correcting the relative sea-level rise measured by a tide gauge instrument by the absolute vertical motion of the instrument, either modeled [1] or measured [2]. Système d'Observation du Niveau des Eaux Littorales (SONEL) [3], National Aeronautics and Space Administration (NASA) Jet Propulsion Laboratory (JPL) [4], and Nevada Geodetic Lab (NGL), [5], also [6], provide estimations of the absolute (geocen-

\footnotetext{
*Corresponding Author: Alberto Boretti, Department of Mechanical Engineering, College of Engineering, Prince Mohammad Bin Fahd University, Al Khobar, Saudi Arabia
}

tric) vertical velocities from continuous Global Navigation Satellite System (GNSS) measurements at fixed locations nearby tide gauges. GNSS time series are obtained from a constellation of satellites which is used for navigation and measurements of the precise geodetic position of antennas. Monthly average mean sea level (MSL) observations in tide gauge locations are provided by Permanent Service for Mean Sea Level (PSMSL) [7]. While an analysis of the PSMSL data permits to estimate the relative rate of rise of the sea levels for these stations, the analysis of the SONEL data permits to estimate the absolute vertical velocity nearby some of the stations, and compute for these stations an absolute rate of rise.

There are requirements for determining the trend, in case of tide gauges length of the period, completeness, quality, and additionally, in case of the GNSS antennas, the stability of the solution. In case of tide gauges, the sea levels oscillate with well-known periodicities in the 60year range, like other climate parameters $[8,9]$, more than 60 years of continuous recording from the same tide gauge, without any major perturbation, are needed to compute a reliable slope by linear fitting, and more than 90 years are needed to compute a reliable acceleration by the parabolic fitting.

SONEL computes the absolute rates of rise of the sea levels from their GNSS data and the tide gauge data from PSMSL. Only 83 locations are shown worldwide in their latest analysis if a maximum time window 1900 to 2013 is selected. Only 9 locations are shown along the East Coast of the US and Canada, only Halifax in Canada, then 9 locations in the US, Newport, New York, Philadelphia, Atlantic City, Annapolis, Baltimore, Washington DC, Charleston, Key West.

As there are 33 Long Term Trend (LTT) tide stations along the East Coast of North America where their measured MSL relative to the tide gauge instrument are given by the PSMSL, there is the opportunity to compute the absolute sea-level rates of rise in more locations.

Analyses of the MSL data are offered by different providers such as the above-mentioned PSMSL, SONEL, sealevel.info [10], and National Oceanic and Atmospheric Administration (NOAA, [11]). 
While the analysis of sea level data is straightforward, the analysis of GNSS data is more troublesome, hence there is a need to use multiple providers. While SONEL is directly linked to PSMSL, it only considers a small number of GNSS antennas, 496 as per June 2018 to cover the world, with data not always up-to-date. JPL has a more extensive database of GNSS antennas, 2,822, albeit not comparable to the NGL database [5], that is by far the most extensive, with 15,277 antennas.

It is widespread to correct the relative sea-level rise trend by a GIA computation such as [1, 12, 13]. However, global GIA models only account in everything but a perfect way for only one of the many components of land motion, the deformation of the Earth's crust in response to changes in the polar ice caps, completely neglecting regional subsidence and crustal movement. Land subsidence is a global problem, especially relevant in the United States, where more than $45,000 \mathrm{~km}^{2}$ of land [14], have been directly affected by subsidence. The principal causes are aquifer-system compaction, hydro-compaction, natural compaction, underground mining, drainage of organic soils, sinkholes, and thawing permafrost [15]. Nearly the entire East Coast of the United States, from Massachusetts and parts of Maine to Florida, is known to be affected by subsidence [16-19].

Except in the very few cases where the GNSS antenna is co-located with the tide gauge, and precise leveling is ensured between the GNSS antenna and the tide gauge instrument, there is no guarantee that the absolute vertical velocity of an inland GNSS antenna is an accurate estimation of the absolute vertical velocity of the tide gauge instrument. However, the GNSS monitoring of the position of antennas certainly provides a much better-quality estimation of the local absolute vertical velocity than a global glacial isostatic adjustment (GIA) model computation. It is well accepted that the correction of the relative rate of rise of the sea level by the absolute velocity of a GNSS antenna nearby the tide gauge returns the absolute rate of rise of the sea levels with higher accuracy [2]. The need for a GNSS antenna co-located with the tide gauge is stressed by [20]. The GIA correction has been seriously questioned by [21].

If the GNSS correction is more accurate than the correction by a global GIA model that does not include any regional subsidence or crustal movements, nevertheless many technicalities limit the accuracy of the GNSS vertical velocity estimation for a specific location, for the same antenna different providers may propose different values of the absolute vertical velocity, and nearby antennas may exhibit a strongly variable pattern of subsidence not always genuine.
In the following sections, one relative MSL result, and multiple GNSS results are proposed for every selected tide gauge location, in addition to the GIA estimations. While the subsidence rate will be based on the NGL GNSS results [5], the other estimations help to understand the uncertainties in the assumption.

\section{Method}

Two regressions are usually applied to the measured relative sea levels of a tide gauge record to compute the relative sea-level rate of rise and acceleration. A linear regression:

$$
y(x)=A+B \cdot x
$$

returns the sea level rate of rise $\boldsymbol{u}$ as the slope B. A quadratic regression

$$
y(x)=A^{\prime}+B^{\prime} \cdot x+C \cdot x^{2}
$$

returns the acceleration $\boldsymbol{a}$ taken as 2.C. The linear regression is also applied to the absolute vertical position of the GNSS record for antennas located nearby tide gauge installations. The linear regression now returns the absolute velocity $\boldsymbol{w}$ as the slope B. The absolute rates of rise of the sea levels are then computed as $\boldsymbol{v}=\boldsymbol{u}+\boldsymbol{w}$ [2].

\section{Results}

Presented below are the analyses of the relative rates of rise and accelerations of the sea level in the 33 Long Term Trend (LTT) tide stations of the East Coast of North America. Figure 1 presents a map with the relative sea-level rise trends in the locations with more than 80 years of data in the PSMSL database, with the East Coast of North America in evidence. The PSMSL map only shows Halifax and TroisRivieres in Canada, then the US stations between Portland and Key West. Galveston, that in the Gulf of Mexico, and not strictly speaking East Coast of North America is also shown. Galveston is located in a well-known area of extreme subsidence for oil and groundwater extraction.

Table 1 summarizes the relative rates of rise and accelerations for the 33 stations that are considered in the survey. $\boldsymbol{u}$ is the relative sea-level rise, $\boldsymbol{w}$ is the absolute vertical velocity at the GNSS antenna nearby the tide gauge, and $\boldsymbol{v}=\boldsymbol{u}+\boldsymbol{w}$ is the absolute sea-level rise. Table 1 summarizes the tide gauge results as well as the results at the nearby GNSS antennas, and the results of two GIA models. The absolute rates of rise of the sea levels are computed based 


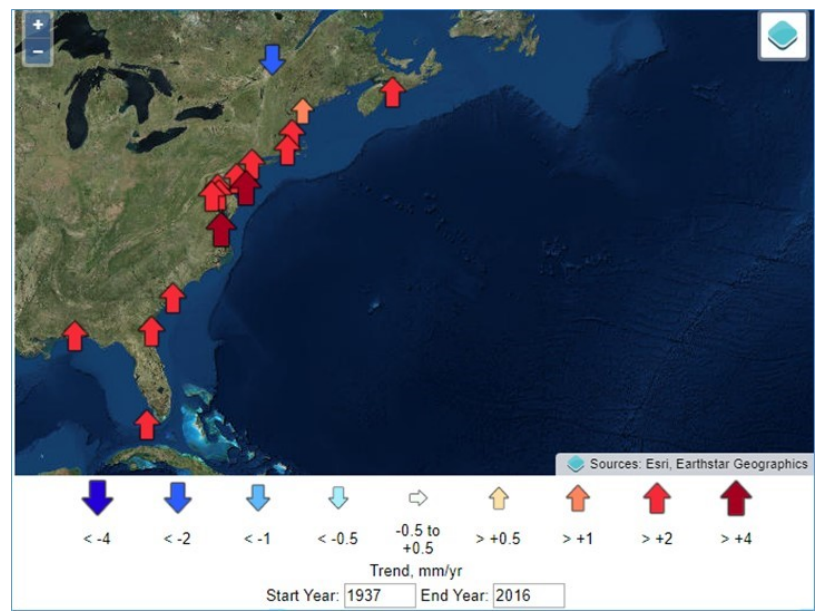

Figure 1: Locations of the tide gauges with more than 80 years of data in the PSMSL database. Image reproduced modified after [7]. Northern-most station is Trois Riviere, Southern-most station is Key West.

on these data. The table proposes as $\boldsymbol{w}^{*}$ the Glacial Isostatic Adjustment (GIA) vertical velocities VM2 and VM4 from [12, 13]. The VM2 and VM4 data are presently available at [22]. This page has two links for Peltier's files, [23] (VM2) and [24] (VM4). The second link is now broken also in the archived versions. The data contains a known error, which was discovered in March 2012, that is however irrelevant for the paper.

Figures 2 to 16 present the details of the monthly average mean sea levels (MSL) as well as the GPS position for the more representative 15 stations, having more than 100 years of data. MSL images are from sealevel.info. GPS images are reproduced modified after [5].

\subsection{Saint John, N.B., Canada}

The MSL trend at Saint John, N.B., Canada, Figure 2, is $+2.14 \mathrm{~mm} /$ year with a $95 \%$ confidence interval of \pm 0.20 $\mathrm{mm}$ /year, based on MSL data from 1896/6 to 2016/12. The acceleration is $-0.00631 \pm 0.01237 \mathrm{~mm} / \mathrm{yr}^{2}$.

Saint John, N.B., Canada has no nearby GNSS stations from SONEL. JPL also has no station nearby. NGL has STJH, of absolute vertical velocity $-0.177 \pm 12.814 \mathrm{~mm} / \mathrm{yr}$., SJNB, of absolute vertical velocity $-0.664 \pm 1.052 \mathrm{~mm} / \mathrm{yr}$. and SJPA, of absolute vertical velocity $-0.697 \pm 0.717 \mathrm{~mm} / \mathrm{yr}$. A likely estimation of the absolute vertical velocity is taken as -0.697 $\mathrm{mm} / \mathrm{yr}$., the subsidence of the NGL station of SJPA, the one with more data and still operational.

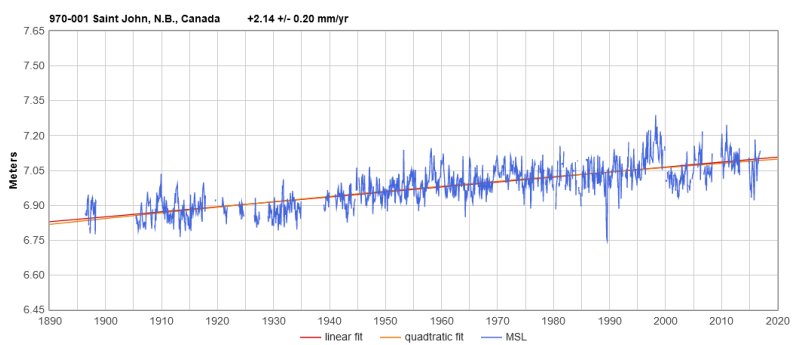

(a)

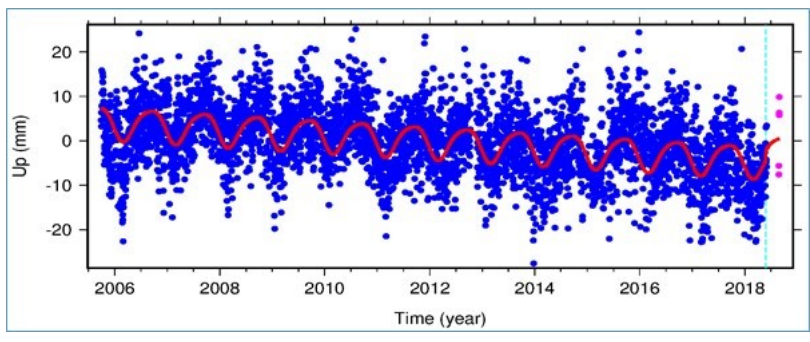

(b)

Figure 2: a) MSL data for Saint John, N.B., Canada. Image reproduced modified after [10]. b) GNSS time series for SJPA. Image reproduced modified after [5].

\subsection{Halifax, Canada}

The MSL trend at Halifax, Canada, Figure 3, is +3.18 $\mathrm{mm} /$ year with a $95 \%$ confidence interval of $\pm 0.13 \mathrm{~mm} /$ year, based on MSL data from 1895/11 to 2014/7. Acceleration is $-0.001387 \pm 0.008732 \mathrm{~mm} / \mathrm{yr}^{2}$.

Halifax, Canada has the nearby GNSS Station from SONEL of HLFX, having absolute vertical velocity $-1.11 \pm 0.18$ $\mathrm{mm} / \mathrm{yr}$. The distance to the tide gauge is $3,100 \mathrm{~m}$. From JPL, HLFX has absolute vertical velocity $-1.07 \pm 0.213$ $\mathrm{mm} / \mathrm{yr}$. From NGL, HLFX has absolute vertical velocity $0.895 \pm 0.552 \mathrm{~mm} / \mathrm{yr}$.

A likely estimation of the absolute vertical velocity is taken as $-0.895 \mathrm{~mm} / \mathrm{yr}$., the NGL result for HLFX.

\subsection{Charlottetown, Canada}

The MSL trend at Charlottetown, Figure 4, is +3.20 $\mathrm{mm} /$ year with a $95 \%$ confidence interval of $\pm 0.16 \mathrm{~mm} /$ year, based on MSL data from 1911/4 to 2016/12. The acceleration is $-0.00230 \pm 0.01056 \mathrm{~mm} / \mathrm{yr}^{2}$.

Charlottetown, Canada has no nearby GNSS station from SONEL. JPL also has no stations nearby. NGL has PETI, of absolute vertical velocity $-1.751 \pm 1.520 \mathrm{~mm} / \mathrm{yr}$. A likely estimation of the absolute vertical velocity is taken as $-1.751 \mathrm{~mm} / \mathrm{yr}$., the NGL result for PETI. 
Table 1: Summary of sea-level rise and subsidence results. $\boldsymbol{u}$ is the relative sea-level rise, $\boldsymbol{w}$ is the absolute vertical velocity at the GNSS antenna nearby the tide gauge, or computed with a GIA model, and $\boldsymbol{v}=\boldsymbol{u}+\boldsymbol{w}$ is the absolute sea-level rise.

\begin{tabular}{|c|c|c|c|c|c|c|c|c|c|c|c|}
\hline \multirow[b]{2}{*}{ Station } & \multirow[b]{2}{*}{ Start } & \multirow[b]{2}{*}{ End } & \multirow[b]{2}{*}{ Range } & \multirow[b]{2}{*}{$\begin{array}{c}\mathrm{u} \\
\mathrm{mm} / \mathrm{yr} .\end{array}$} & \multirow[b]{2}{*}{$\begin{array}{c}a \\
\mathrm{~mm} / \mathrm{yr}^{2}\end{array}$} & \multicolumn{2}{|c|}{ GNSS } & \multicolumn{4}{|c|}{ Peltier GIA } \\
\hline & & & & & & $\begin{array}{c}\mathbf{w} \\
\mathrm{mm} / \mathrm{yr}\end{array}$ & $\begin{array}{c}\mathbf{v} \\
\mathrm{mm} / \\
\mathrm{yr} .\end{array}$ & $\begin{array}{c}\mathbf{w}^{\star} \text { VM2 } \\
\mathrm{mm} / \\
\mathrm{yr} .\end{array}$ & $\begin{array}{c}\mathbf{w}^{\star} \text { VM4 } \\
\text { mm/ } \\
\text { yr. }\end{array}$ & $\begin{array}{l}\mathbf{v}^{\star} \text { VM2 } \\
\mathrm{mm} / \\
\text { yr. }\end{array}$ & $\begin{array}{l}\mathrm{v}^{\star} \text { VM4 } \\
\mathrm{mm} / \\
\text { yr. }\end{array}$ \\
\hline Saint John, N.B., Canada & 1896.46 & 2016.96 & 120.50 & 2.14 & -0.0063 & -0.70 & 1.44 & -0.70 & -0.43 & 1.44 & 1.71 \\
\hline Halifax, Canada & 1895.87 & 2014.54 & 118.67 & 3.18 & -0.0014 & -0.90 & 2.29 & -1.21 & -0.66 & 1.97 & 2.52 \\
\hline Charlottetown, Canada & 1911.29 & 2016.96 & 105.67 & 3.20 & -0.0023 & -1.75 & 1.45 & -2.20 & -1.92 & 1.00 & 1.28 \\
\hline Pointe-Au-Pere, Canada & 1900.04 & 1983.96 & 83.92 & -0.37 & 0.0829 & 2.03 & 1.66 & -0.51 & -1.35 & -0.88 & -1.72 \\
\hline Quebec, Canada & 1910.04 & 2012.79 & 102.75 & -0.24 & -0.0350 & 2.32 & 2.08 & 0.67 & 0.08 & 0.43 & -0.16 \\
\hline Deschaillons, Canada & 1915.37 & 2016.96 & 101.59 & 0.25 & -0.0556 & 0.77 & 1.02 & 0.92 & 0.33 & 1.17 & 0.58 \\
\hline Trois-Rivieres, Canada & 1899.79 & 2016.96 & 117.17 & -1.43 & -0.0440 & 0.77 & -0.66 & 0.96 & 0.42 & -0.47 & -1.01 \\
\hline Batiscan, Canada & 1901.37 & 2016.96 & 115.59 & -1.49 & -0.0376 & 0.77 & -0.72 & 0.94 & 0.36 & -0.55 & -1.13 \\
\hline Neuville, Canada & 1914.46 & 2015.96 & 101.50 & 0.05 & -0.0266 & 0.77 & 0.82 & 0.79 & 0.21 & 0.84 & 0.26 \\
\hline Harrington $\mathrm{Hbr}$, Canada & 1910.62 & 1989.62 & 79.00 & -0.63 & -0.0216 & 1.40 & 0.77 & 1.66 & 1.53 & 1.03 & 0.90 \\
\hline St John's, Nfld., Canada & 1935.62 & 2015.96 & 80.34 & 2.06 & 0.0016 & -0.79 & 1.27 & -1.07 & -0.38 & 0.99 & 1.68 \\
\hline Eastport, ME, USA & 1929.79 & 2017.88 & 88.09 & 2.13 & -0.0172 & 0.10 & 2.23 & -0.42 & -0.13 & 1.71 & 2.00 \\
\hline Portland, ME, USA & 1912.04 & 2017.96 & 105.92 & 1.87 & -0.0069 & 0.90 & 2.77 & -0.46 & -0.10 & 1.41 & 1.77 \\
\hline Boston, MA, USA & 1921.04 & 2017.96 & 96.92 & 2.82 & -0.0030 & -0.84 & 1.98 & -1.32 & -0.72 & 1.50 & 2.10 \\
\hline Woods Hole, MA, USA & 1932.62 & 2017.96 & 85.34 & 2.86 & 0.0172 & 0.24 & 3.10 & -1.89 & -1.11 & 0.97 & 1.75 \\
\hline Newport, RI, USA & 1930.79 & 2017.96 & 87.17 & 2.75 & 0.0113 & -0.25 & 2.50 & -1.80 & -1.04 & 0.95 & 1.71 \\
\hline Kings Pt/Willets Pt, NY, USA & 1931.62 & 2016.87 & 85.25 & 2.50 & 0.0007 & -0.83 & 1.67 & -1.67 & -0.88 & 0.83 & 1.62 \\
\hline The Battery, NY, USA & 1856.04 & 2018.21 & 162.17 & 2.85 & 0.0085 & -2.15 & 0.70 & -1.64 & -0.85 & 1.21 & 2.00 \\
\hline Sandy Hook, NJ, USA & 1932.87 & 2017.96 & 85.09 & 4.07 & 0.0063 & -2.22 & 1.85 & -1.68 & -0.85 & 2.39 & 3.22 \\
\hline Atlantic City, NJ, USA & 1911.71 & 2017.96 & 106.25 & 4.08 & 0.0123 & -1.48 & 2.60 & -1.65 & -0.71 & 2.43 & 3.37 \\
\hline Philadelphia, PA, USA & 1900.54 & 2017.96 & 117.42 & 2.94 & 0.0161 & -0.53 & 2.41 & -1.49 & -0.64 & 1.45 & 2.30 \\
\hline Lewes, DE, USA & 1919.12 & 2017.96 & 98.84 & 3.44 & 0.0202 & -1.06 & 2.38 & -1.45 & -0.49 & 1.99 & 2.95 \\
\hline Baltimore, MD, USA & 1902.46 & 2017.96 & 115.50 & 3.15 & 0.0038 & -1.20 & 1.95 & -1.21 & -0.34 & 1.94 & 2.81 \\
\hline Annapolis, MD, USA & 1928.71 & 2017.96 & 89.25 & 3.57 & -0.0036 & -1.55 & 2.02 & -1.18 & -0.29 & 2.39 & 3.28 \\
\hline $\begin{array}{r}\text { Solomon's Island (Biol. Lab.), MD, } \\
\text { USA }\end{array}$ & 1937.96 & 2017.96 & 80.00 & 3.78 & 0.0544 & -2.35 & 1.43 & -1.11 & -0.17 & 2.67 & 3.61 \\
\hline Washington, DC, USA & 1924.96 & 2017.96 & 93.00 & 3.22 & -0.0005 & -0.19 & 3.03 & -1.11 & -0.22 & 2.11 & 3.00 \\
\hline Sewells Point, VA, USA & 1927.62 & 2017.96 & 90.34 & 4.62 & 0.0182 & -2.01 & 2.61 & -1.01 & -0.05 & 3.61 & 4.57 \\
\hline Wilmington, NC, USA & 1935.37 & 2017.96 & 82.59 & 2.29 & 0.0302 & -1.53 & 0.76 & -0.88 & -0.04 & 1.41 & 2.25 \\
\hline Charleston, SC, USA & 1921.79 & 2017.96 & 96.17 & 3.27 & -0.0039 & -1.30 & 1.97 & -0.83 & -0.10 & 2.44 & 3.17 \\
\hline Fort Pulaski, GA, USA & 1935.04 & 2017.96 & 82.92 & 3.22 & 0.0281 & -0.36 & 2.86 & -0.74 & -0.08 & 2.48 & 3.14 \\
\hline Fernandina Beach, FL, USA & 1897.46 & 2017.96 & 120.50 & 2.11 & 0.0160 & -0.16 & 1.95 & -0.65 & -0.09 & 1.46 & 2.02 \\
\hline Mayport, FL, USA & 1928.37 & 2016.87 & 88.50 & 2.58 & 0.0152 & -0.16 & 2.42 & -0.64 & -0.11 & 1.94 & 2.47 \\
\hline \multirow[t]{2}{*}{ Key West, FL, USA } & 1913.04 & 2018.21 & 105.17 & 2.42 & 0.0141 & -2.92 & -0.50 & -0.38 & -0.18 & 2.04 & 2.24 \\
\hline & & & averages & 2.22 & 0.0028 & -0.52 & 1.70 & -0.76 & -0.33 & 1.46 & 1.89 \\
\hline
\end{tabular}

\subsection{Pointe-Au-Pere, Canada}

Pointe-Au-Pere, Canada, is an LTT tide gauge shorter than 100 years. This location is on the St. Lawrence River, close to the Gulf of St. Lawrence. The nearby GNSS Station from SONEL is PPER, of signal not robust. The distance to the tide gauge is only $206 \mathrm{~m}$. Per JPL, PPER has an absolute vertical velocity of $2.527 \pm 1.679 \mathrm{~mm} / \mathrm{yr}$. NGL also has PPER, of absolute vertical velocity $3.373 \pm 0.863 \mathrm{~mm} / \mathrm{yr}$. plus RIMO, of absolute vertical velocity $0.683 \pm 1.622 \mathrm{~mm} / \mathrm{yr}$. A likely estimation of the absolute vertical velocity in table 1 is taken as $2.028 \mathrm{~mm} / \mathrm{yr}$., an average of the NGL results for PPER and RIMO.

\subsection{Quebec, Canada}

The MSL trend in Quebec, Canada, Figure 5, is -0.26 $\mathrm{mm} /$ year with a $95 \%$ confidence interval of $\pm 0.45 \mathrm{~mm} /$ year, based on MSL data from 1910/1 to 2012/10. The acceleration is $-0.0367 \pm 0.0314 \mathrm{~mm} / \mathrm{yr}^{2}$.

The station is along the St. Lawrence River, but upstream of Pointe-Au-Pere.

Quebec, Canada has no nearby GNSS station from SONEL. JPL also has no station nearby. NGL has ATR1, of absolute vertical velocity $0.643 \pm 1.847 \mathrm{~mm} / \mathrm{yr}$.; ANG7, of absolute vertical velocity $2.698 \pm 1.018 \mathrm{~mm} / \mathrm{yr}$.; LAVE, of absolute vertical velocity $3.606 \pm 2.356 \mathrm{~mm} / \mathrm{yr}$.; LEVI, of absolute 


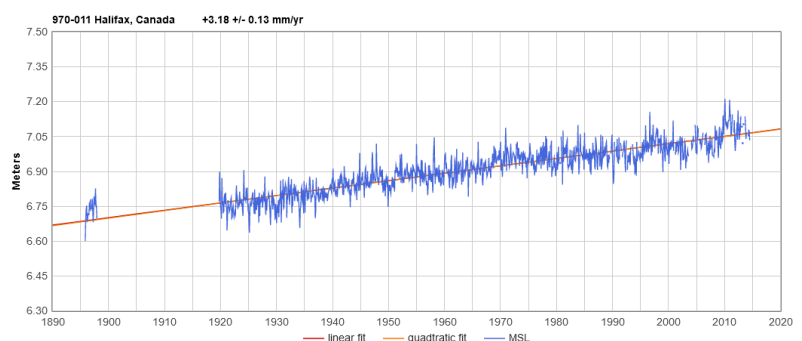

(a)

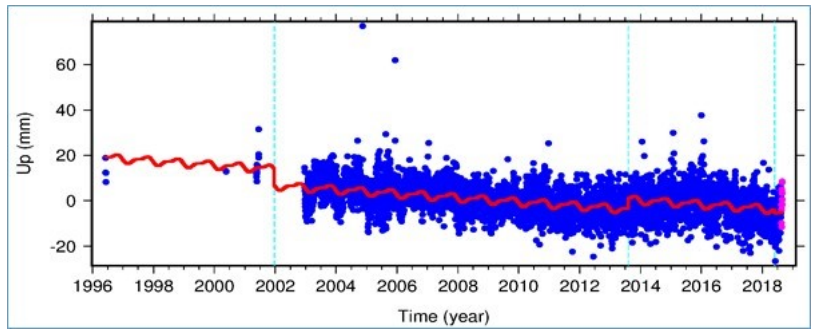

(b)

Figure 3: a) MSL data for Halifax, Canada. Image reproduced modified after [10]. b) GNSS time series for HLFX. Image reproduced modified after [5].

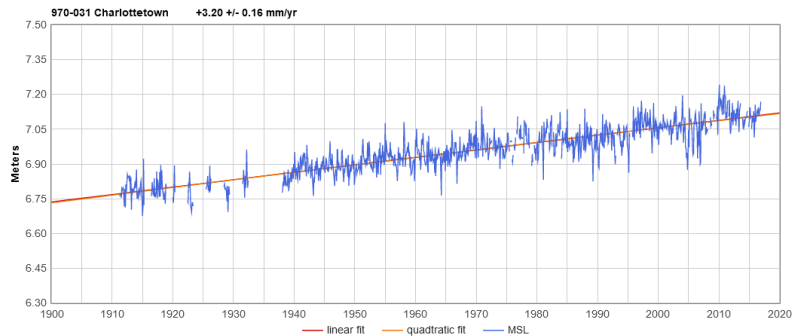

(a)

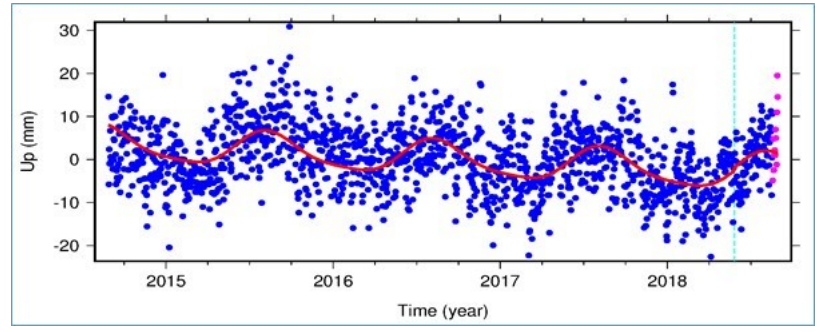

(b)

Figure 4: a) MSL data for Charlottetown. Image reproduced modified after [10]. b) GNSS time series for PETI. Image reproduced modified after [5].

vertical velocity $1.847 \pm 1.102 \mathrm{~mm} / \mathrm{yr}$. and VALB, of absolute vertical velocity $2.732 \pm 1.353 \mathrm{~mm} / \mathrm{yr}$. A likely estimation of the absolute vertical velocity is taken as $2.3052 \mathrm{~mm} / \mathrm{yr}$., an average of the NGL results.

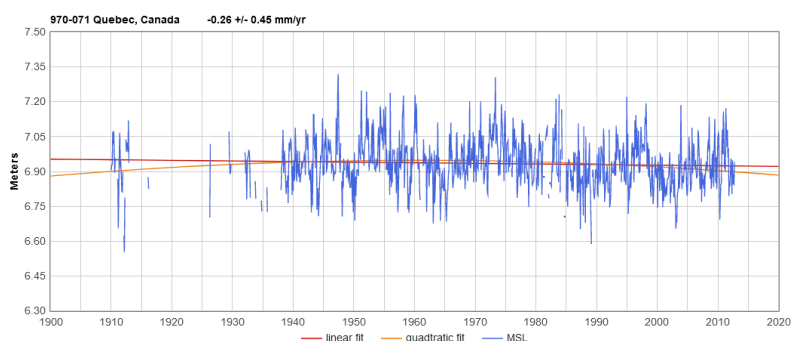

(a)

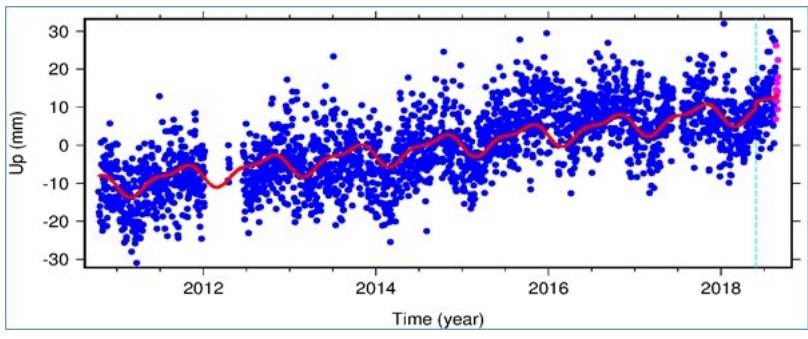

(b)

Figure 5: a) MSL data for Quebec. Image reproduced modified after [10]. b) GNSS time series for ANG7. Image reproduced modified after [5].

\subsection{Deschaillons, Canada}

The MSL trend at Deschaillons, Canada, Figure 6, is +0.25 $\mathrm{mm} /$ year with a $95 \%$ confidence interval of $\pm 1.46 \mathrm{~mm} /$ year, based on MSL data from 1915/5 to 2016/12. The acceleration is $-0.0556 \pm 0.1069 \mathrm{~mm} / \mathrm{yr}^{2}$.

Deschaillons, Canada is on the St. Lawrence River, south of Quebec. It has no nearby GNSS station from SONEL. JPL also has no station nearby. In Trois Riviere, further south, NGL has BECA, of absolute vertical velocity $2.318 \pm 0.958 \mathrm{~mm} / \mathrm{yr}$.; $3 \mathrm{RIV}$, of absolute vertical velocity $1.742 \pm 0.263 \mathrm{~mm} / \mathrm{yr}$.; TRI2, of absolute vertical velocity $0.482 \pm 2.429 \mathrm{~mm} / \mathrm{yr}$.; and PTDL, of absolute vertical velocity $-1.445 \pm 1.040 \mathrm{~mm} / \mathrm{yr}$. A likely estimation of the absolute vertical velocity in Trois Riviere is taken as $0.77425 \mathrm{~mm} / \mathrm{yr}$., an average of the NGL results.

\subsection{Trois-Rivieres, Canada}

The MSL trend at Trois-Rivieres, Figure 7, is $-1.43 \mathrm{~mm} /$ year with a $95 \%$ confidence interval of $\pm 1.84 \mathrm{~mm} /$ year, based on MSL data from $1899 / 10$ to $2016 / 12$. The acceleration is $-0.0440 \pm 0.1225 \mathrm{~mm} / \mathrm{yr}^{2}$.

Trois-Rivieres, Canada is further south on the St. Lawrence River. SONEL and JPL have no station nearby, NGL has those stations listed before. A likely estimation of the absolute vertical velocity is taken as $0.77425 \mathrm{~mm} / \mathrm{yr}$., same as above. 


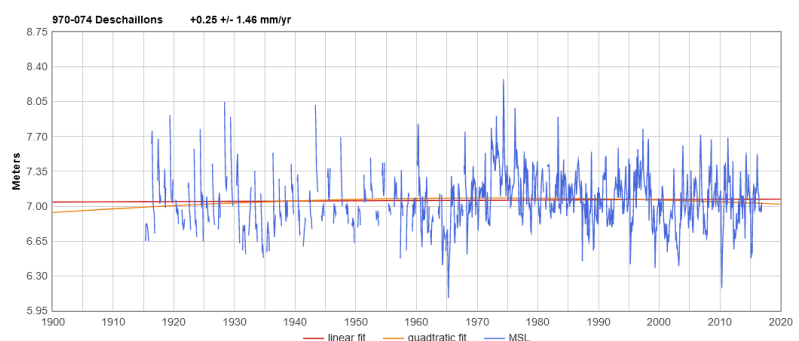

(a)

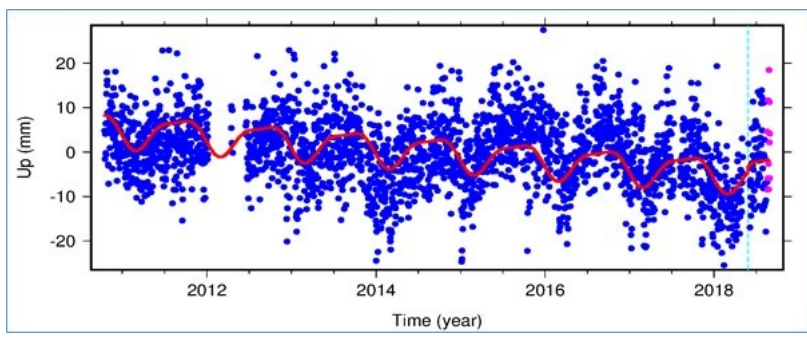

(b)

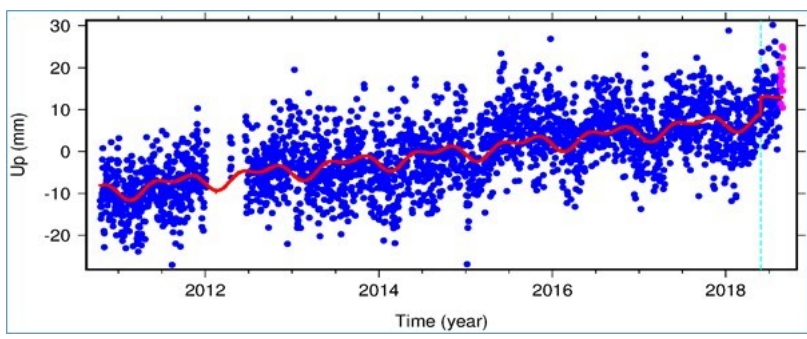

(c)

Figure 6: a) MSL data for Deschaillons. Image reproduced modified after [10]. b) GNSS time series for PTDL. Image reproduced modified after [5]. c) GNSS time series for BECA. Image reproduced modified after [5].

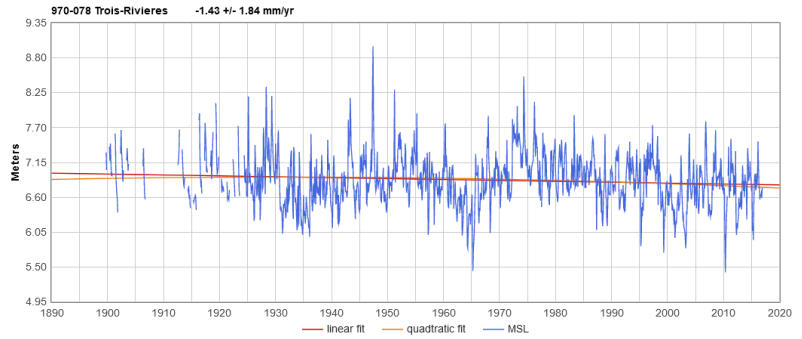

Figure 7: MSL data for Trois-Rivieres. Image reproduced modified after [10].

\subsection{Batiscan, Canada}

The MSL trend at Batiscan, Figure 8 , is $-1.49 \mathrm{~mm} /$ year with a $95 \%$ confidence interval of $\pm 1.81 \mathrm{~mm} /$ year, based on MSL data from $1901 / 5$ to $2016 / 12$. The acceleration is -0.0376 $\pm 0.1248 \mathrm{~mm} / \mathrm{yr}^{2}$.

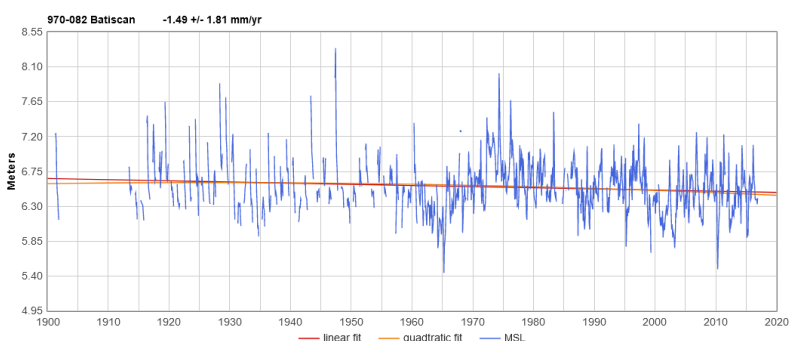

Figure 8: MSL data for Batiscan. Image reproduced modified after [10].

Batiscan, Canada is also on the St. Lawrence River, south of Quebec, north of Trois-Rivieres. In absence of any data from SONEL and JPL, a likely estimation of the absolute vertical velocity is taken as $0.77425 \mathrm{~mm} / \mathrm{yr}$., the same as above.

\subsection{Neuville, Canada}

The MSL trend at Neuville, Canada, Figure 9, is +0.05 $\mathrm{mm} /$ year with a $95 \%$ confidence interval of $\pm 0.70 \mathrm{~mm}$ /year, based on MSL data from 1914/6 to 2016/12. The acceleration is $-0.0266 \pm 0.0520 \mathrm{~mm} / \mathrm{yr}^{2}$.

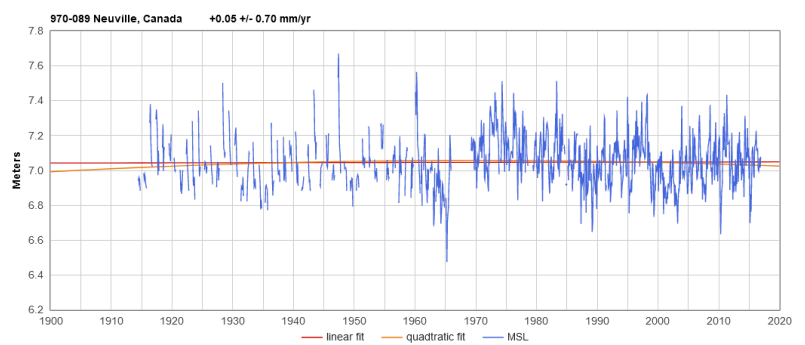

Figure 9: MSL data for Neuville, Canada. Image reproduced modified after [10].

Neuville, Canada is also on the St. Lawrence River, south of Quebec, north of Trois-Rivieres.

In absence of any data from SONEL and JPL, a likely estimation of the absolute vertical velocity is taken as 0.77425 $\mathrm{mm} / \mathrm{yr}$., the same as above.

Worth to mention, are GNSS antennas inland from the St. Lawrence River between Trois-Rivieres and Quebec. From NGL, QCSM has an absolute vertical velocity $-0.878 \pm 3.110 \mathrm{~mm} / \mathrm{yr}$. and LAUR has absolute vertical velocity $2.367 \pm 1.021 \mathrm{~mm} / \mathrm{yr}$. Hence, more GNSS data are certainly needed to resolve this region. 


\subsection{Harrington Hbr and St John's Nfld., Canada}

For the other stations of Canada, of length less than 100 years, the subsidence rates in Table 1 are selected as follows.

Harrington Hbr, Canada, in the Gulf of St. Lawrence, close to the ocean, has no data from SONEL, no data from JPL. From NGL, but relatively far, there are HST2, of absolute vertical velocity $0.619 \pm 2.035 \mathrm{~mm} / \mathrm{yr}$.; HVRP, of absolute vertical velocity $3.003 \pm 1.796 \mathrm{~mm} / \mathrm{yr}$.; CBR1, of absolute vertical velocity $0.606 \pm 2.127 \mathrm{~mm} / \mathrm{yr}$. A likely estimation of the absolute vertical velocity is taken as $1.4 \mathrm{~mm} / \mathrm{yr}$., an average of the NGL results.

St John's, Nfld., Canada, is on the ocean. It has the nearby GNSS Stations from SONEL of STJ3, of no data, and then STJO, of absolute vertical velocity $-0.10 \pm 0.13 \mathrm{~mm} / \mathrm{yr}$. According to NGL, there are STJ3, of absolute vertical velocity $-1.265 \pm 2.346 \mathrm{~mm} / \mathrm{yr}$. and STJO, of absolute vertical velocity $-0.309 \pm 0.595 \mathrm{~mm} / \mathrm{yr}$. A likely estimation of the absolute vertical velocity is taken as $-0.787 \mathrm{~mm} / \mathrm{yr}$. - average of the NGL results also here.

\subsection{Eastport and Portland, United States}

Then, moving south, within the US, the first station with more than 100 years of data is Portland. Before Portland, there is Eastport. Eastport, ME, United States has the nearby GNSS Station from SONEL EPRT, of absolute vertical velocity $0.28 \pm 0.25 \mathrm{~mm} / \mathrm{yr}$. The distance to the tide gauge is $853 \mathrm{~m}$. NGL has

EPRT, of absolute vertical velocity $0.103 \pm 0.863 \mathrm{~mm} / \mathrm{yr}$. A likely estimation of the absolute vertical velocity is taken as $0.103 \mathrm{~mm} / \mathrm{yr}$., the NGL result for EPRT. This is the value used in Table 1.

The MSL trend at Portland, ME, United States, Figure 10 , is $+1.87 \mathrm{~mm} /$ year with a $95 \%$ confidence interval of $\pm 0.15 \mathrm{~mm} /$ year, based on MSL data from 1912/1 to 2017/12. The acceleration is $-0.00694 \pm 0.01079 \mathrm{~mm} / \mathrm{yr}^{2}$.

Portland, ME, United States has no nearby GNSS antenna according to SONEL. JPL has YMTS, of absolute vertical velocity $0.139 \pm 0.611 \mathrm{~mm} / \mathrm{yr}$. NGL has MEGO, of absolute vertical velocity $1.277 \pm 1.043 \mathrm{~mm} / \mathrm{yr}$. and MEYA, of absolute vertical velocity $0.529 \pm 0.725 \mathrm{~mm} / \mathrm{yr}$. A likely estimation of the absolute vertical velocity is taken as $0.903 \mathrm{~mm} / \mathrm{yr}$., an average of NGL results.

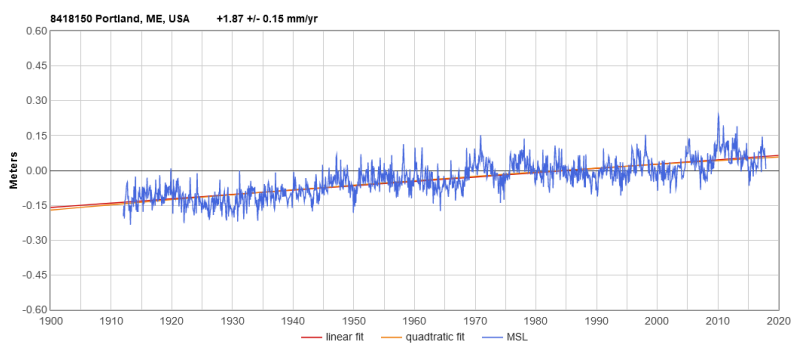

(a)

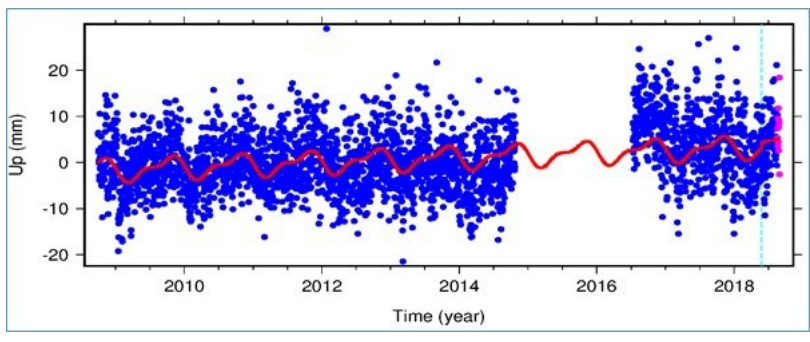

(b)

Figure 10: a) MSL data for Portland, ME, United States. Image reproduced modified after [10]. b) GNSS time series for MEYA. Image reproduced modified after [5].

\subsection{Boston, Woods Hole, Newport, and Kings Pt/Willets Pt, United States}

In between Portland and NY, there are several tide gauges of length less than 100 years. The subsidence rates in Table 1 are obtained as follows.

Boston, MA, United States has no nearby GNSS antenna according to SONEL. JPL also has no data. NGL has MAMI, of absolute vertical velocity $1.018 \pm 1.597 \mathrm{~mm} / \mathrm{yr}$.; MAWB, of absolute vertical velocity $-4.625 \pm 4.273 \mathrm{~mm} / \mathrm{yr}$. and FMTS, of absolute vertical velocity $1.090 \pm 0.892$ $\mathrm{mm} / \mathrm{yr}$. A likely estimation of the absolute vertical velocity is taken as $-0.839 \mathrm{~mm} / \mathrm{yr}$., an average of the NGL results.

Woods Hole, MA, United States has the nearby GNSS Station from SONEL MAFA, of no data. The distance to the tide gauge is $15,290 \mathrm{~m}$. JPL has no nearby stations. NGL has MAF1, of absolute vertical velocity $0.239 \pm 1.418 \mathrm{~mm} / \mathrm{yr}$. A likely estimation of the absolute vertical velocity is taken as $0.239 \mathrm{~mm} / \mathrm{yr}$., the NGL result for MAF1.

Newport, RI, United States has the nearby GNSS Station from SONEL of NPRI, of absolute vertical velocity $0.20 \pm 0.23 \mathrm{~mm} / \mathrm{yr}$. The distance to the tide gauge is $500 \mathrm{~m}$. JPL has NPRI, of absolute vertical velocity $-0.603 \pm 0.308$ $\mathrm{mm} / \mathrm{yr}$. NGL has NPRI, of absolute vertical velocity $0.254 \pm 0.704 \mathrm{~mm} / \mathrm{yr}$. A likely estimation of the absolute vertical velocity is taken as $-0.254 \mathrm{~mm} / \mathrm{yr}$., the NGL result for NPRI. 
Kings Pt/Willets Pt, NY, United States has the nearby GNSS Station from SONEL of NYQN, of absolute vertical velocity $-1.02 \pm 0.30 \mathrm{~mm} / \mathrm{yr}$. The distance to the tide gauge is $9,297 \mathrm{~m}$. While there are no data from JPL, NGL has NYQN, of absolute vertical velocity $-0.834 \pm 0.771 \mathrm{~mm} / \mathrm{yr}$. A likely estimation of the absolute vertical velocity is taken as $0.834 \mathrm{~mm} / \mathrm{yr}$., the NGL result for NYQN.

\subsection{The Battery, United States}

The MSL trend at The Battery, NY, United States, Figure 11, is $+2.85 \mathrm{~mm} /$ year with a $95 \%$ confidence interval of \pm 0.09 $\mathrm{mm}$ /year, based on MSL data from $1856 / 1$ to $2018 / 3$. The acceleration is $0.00849 \pm 0.00388 \mathrm{~mm} / \mathrm{yr}^{2}$.

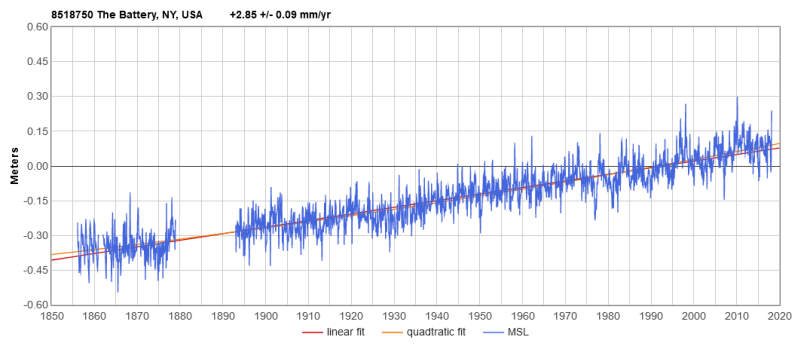

(a)

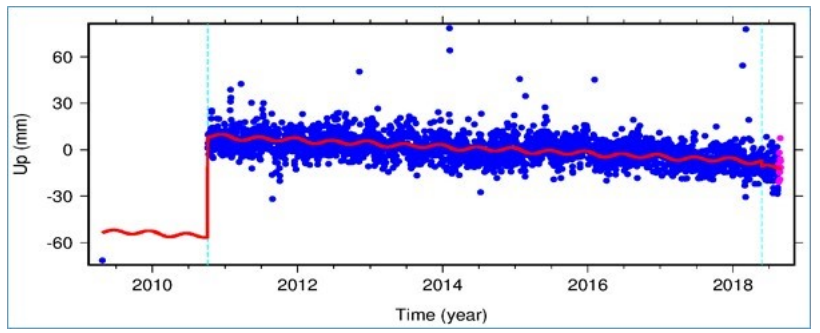

(b)

Figure 11: a) MSL data for The Battery, NY, United States. Image reproduced modified after [10]. b) GNSS time series for NYBP. Image reproduced modified after [5].

The Battery, NY, United States has the nearby GNSS Stations from SONEL of NYBR, with no data, and NYBP, of absolute vertical velocity $-2.12 \pm 0.62 \mathrm{~mm} / \mathrm{yr}$. NYBP is practically co-located at a distance to the tide gauge of only 49 $\mathrm{m}$. JPL has no data. NGL has NYBP, of absolute vertical velocity $-2.152 \pm 0.969 \mathrm{~mm} / \mathrm{yr}$.; and NYBR, of absolute vertical velocity $-1.085 \pm 1.021 \mathrm{~mm} / \mathrm{yr}$. As NYBP is co-located with the tide gauge, a likely estimation of the absolute vertical velocity is taken as $-2.152 \mathrm{~mm} / \mathrm{yr}$., the NGL result for NYBP.

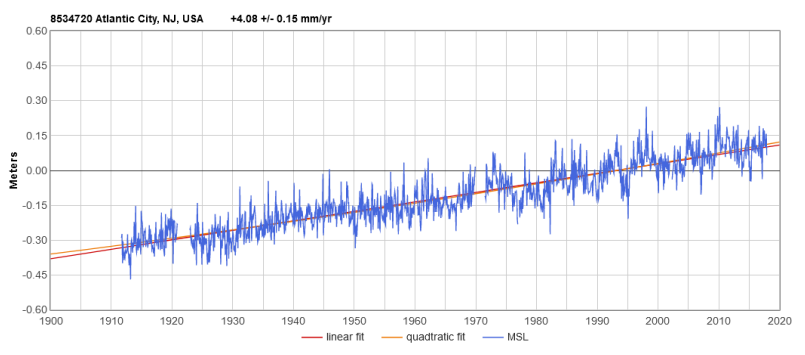

(a)

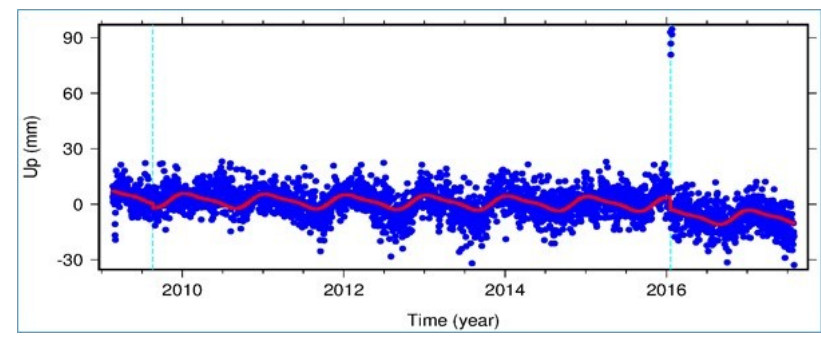

(b)

Figure 12: a) MSL data for Atlantic City, NJ, United States. Image reproduced modified after [10]. b) GNSS time series for NJGT. Image reproduced modified after [5].

\subsection{Sandy Hook, United States}

The subsidence rate in Table 1 for the nearby tide gauge of Sandy Hook of length less than 100 years is given as follows. Sandy Hook, NJ, United States has nearby GNSS Stations from SONEL of SHK1, of absolute vertical velocity $-1.83 \pm 0.29 \mathrm{~mm} / \mathrm{yr}$.; SHK5, of absolute vertical velocity $-2.65 \pm 0.27 \mathrm{~mm} / \mathrm{yr}$.; and SHK6, of no data. SHK1 has a distance to the tide gauge of $553 \mathrm{~m}$, the same as SHK5. SHK6 has a distance to the tide gauge of $563 \mathrm{~m}$. NGL has SHK1, of absolute vertical velocity $-2.242 \pm 0.715 \mathrm{~mm} / \mathrm{yr}$.; SHK2, of absolute vertical velocity $-1.734 \pm 1.019 \mathrm{~mm} / \mathrm{yr}$.; SHK5, of absolute vertical velocity $-2.784 \pm 0.685 \mathrm{~mm} / \mathrm{yr}$; and SHK6, of absolute vertical velocity $-2.127 \pm 0.694 \mathrm{~mm} / \mathrm{yr}$. A likely estimation of the absolute vertical velocity is taken as -2.22175 $\mathrm{mm} / \mathrm{yr}$., an average of the NGL results.

\subsection{Atlantic City, United States}

The MSL trend at Atlantic City, NJ, United States, Figure 12, is $+4.08 \mathrm{~mm} /$ year with a $95 \%$ confidence interval of \pm 0.15 $\mathrm{mm}$ /year, based on MSL data from 1911/9 to 2017/12. The acceleration is $0.01225 \pm 0.01122 \mathrm{~mm} / \mathrm{yr}^{2}$.

Atlantic City, NJ, United States has the nearby GNSS Station from SONEL of NJGT, of absolute vertical velocity $-1.62 \pm 0.66 \mathrm{~mm} / \mathrm{yr}$. The distance to the tide gauge is 16,342 $\mathrm{m}$. NGL has NJGT, of absolute vertical velocity $-0.327 \pm 1.047$ $\mathrm{mm} / \mathrm{yr}$. and NJAC, of absolute vertical velocity $-2.628 \pm 2.161$ 
$\mathrm{mm} / \mathrm{yr}$. A likely estimation of the absolute vertical velocity is taken as $-1.4775 \mathrm{~mm} / \mathrm{yr}$., an average of the NGL results.

\subsection{Philadelphia, United States}

The MSL trend at Philadelphia, PA, United States, Figure 13 , is $+2.94 \mathrm{~mm} /$ year with a $95 \%$ confidence interval of $\pm 0.19 \mathrm{~mm} /$ year, based on MSL data from 1900/7 to 2017/12. The acceleration is $0.01607 \pm 0.01221 \mathrm{~mm} / \mathrm{yr}^{2}$.

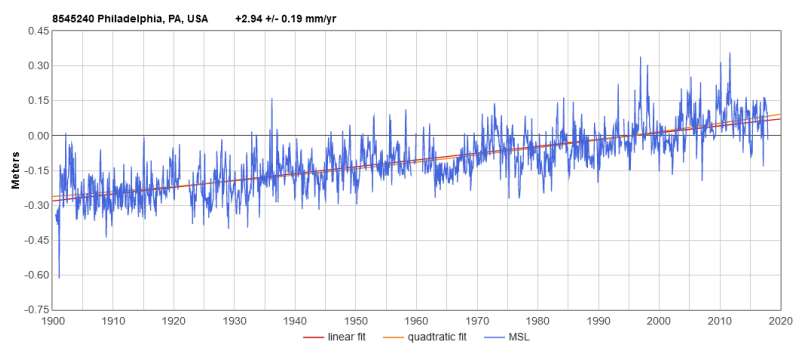

(a)

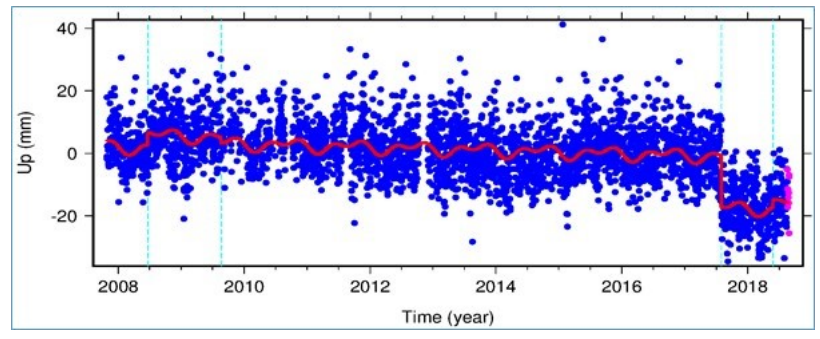

(b)

Figure 13: a) MSL data for Philadelphia, PA, United States. Image reproduced modified after [10]. b) GNSS time series for PAPH. Image reproduced modified after [5].

Philadelphia, PA, United States has the nearby GNSS Station from SONEL of PAPH, of absolute vertical velocity $-0.53 \pm 0.38 \mathrm{~mm} / \mathrm{yr}$. The distance to the tide gauge is 9,390 $\mathrm{m}$. NGL has PAPH, of absolute vertical velocity $-0.533 \pm 1.081$ $\mathrm{mm} / \mathrm{yr}$. A likely estimation of the absolute vertical velocity is taken as $-0.533 \mathrm{~mm} / \mathrm{yr}$., the NGL result for PAPH.

\subsection{Lewes, United States}

Lewes, DE, United States has the nearby GNSS Station from SONEL of CHL1, of absolute vertical velocity $0.48 \pm 0.56 \mathrm{~mm} / \mathrm{yr}$. The distance to the tide gauge is 2,825 $\mathrm{m}$. NGL has CHL1, of absolute vertical velocity $-1.059 \pm 1.055$ $\mathrm{mm} / \mathrm{yr}$. A likely estimation of the absolute vertical velocity is taken as $-1.059 \mathrm{~mm} / \mathrm{yr}$., the NGL result for CHL1.

\subsection{Baltimore, United States}

The MSL trend in Baltimore, MD, United States, Figure 14, is $+3.15 \mathrm{~mm} /$ year with a $95 \%$ confidence interval of \pm 0.13 $\mathrm{mm} /$ year, based on MSL data from 1902/6 to 2017/12. The acceleration is $0.00382 \pm 0.00852 \mathrm{~mm} / \mathrm{yr}^{2}$.

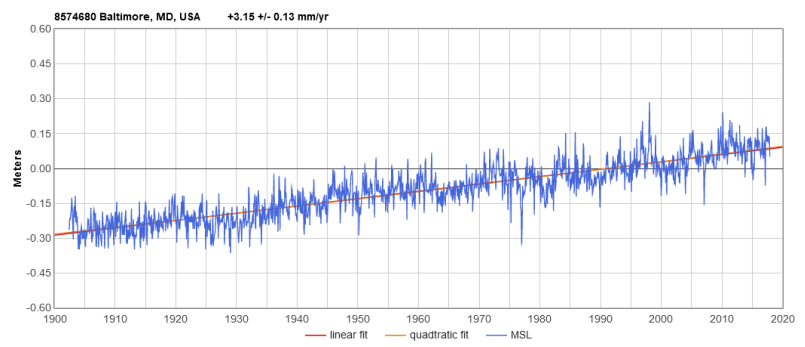

(a)

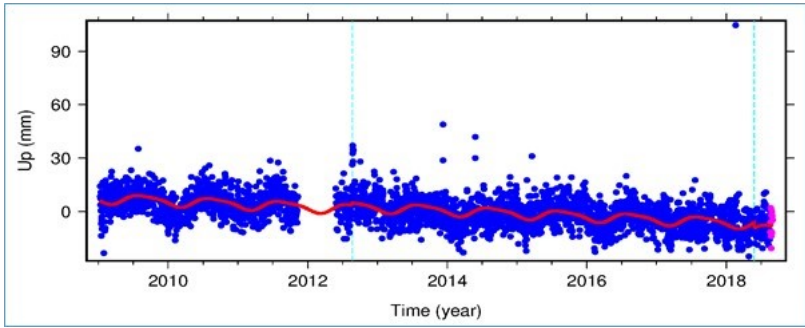

(b)

Figure 14: a) MSL data for Baltimore, MD, United States. Image reproduced modified after [10]. b) GNSS time series for UMBC. Image reproduced modified after [5].

Baltimore, MD, United States has the nearby GNSS Stations from SONEL of SA15, of absolute vertical velocity $1.21 \pm 0.26 \mathrm{~mm} / \mathrm{yr}$.; and UMBC, of absolute vertical velocity $-1.57 \pm 0.52 \mathrm{~mm} / \mathrm{yr}$. The distance to the tide gauge is $11,287 \mathrm{~m}$ (SA15) and 11,446 m (UMBC). NGL has UMBC, of absolute vertical velocity $-1.573 \pm 0.946 \mathrm{~mm} / \mathrm{yr}$. and SA15, of absolute vertical velocity $-0.818 \pm 0.897 \mathrm{~mm} / \mathrm{yr}$.

A likely estimation of the absolute vertical velocity is taken as $-1.1955 \mathrm{~mm} / \mathrm{yr}$., an average of the NGL results.

\subsection{Annapolis, Solomon's Island, Washington, DC, Sewells Point, Wilmington, Charleston, and Fort Pulaski, United States}

South of Baltimore and north of Fernandina Beach there are other tide gauges of length less than 100 years. In these tide gauges, the subsidence rates shown in Table 1 are obtained as follows. 
Annapolis, MD, United States has the nearby GNSS Stations from SONEL of ANP6, of no data, USNA, of absolute vertical velocity $-0.63 \pm 0.53 \mathrm{~mm} / \mathrm{yr}$. ; LOYF, of no data, ANP1, of absolute vertical velocity $-1.03 \pm 0.46 \mathrm{~mm} / \mathrm{yr}$.; and ANP5, of absolute vertical velocity $-2.46 \pm 0.37 \mathrm{~mm} / \mathrm{yr}$. USNA is co-located with the tide gauge, with a distance to the tide gauge of $37 \mathrm{~m}$. NGL has, in addition to the others, USNA, of absolute vertical velocity $-1.551 \pm 1.231 \mathrm{~mm} / \mathrm{yr}$. A likely estimation of the absolute vertical velocity is taken as -1.551 $\mathrm{mm} / \mathrm{yr}$., the NGL result for USNA.

Solomon's Island (Biol. Lab.), MD, United States has the nearby GNSS Stations from SONEL of SOL1, of absolute vertical velocity $-2.62 \pm 0.27 \mathrm{~mm} / \mathrm{yr}$.; and MDSI, of absolute vertical velocity $-1.39 \pm 0.40 \mathrm{~mm} / \mathrm{yr}$. MDSI and SOL1 have a distance to the tide gauge of $308 \mathrm{~m}$. NGL has SOL1, of absolute vertical velocity $-2.720 \pm 0.773 \mathrm{~mm} / \mathrm{yr}$.; and MDSI, of absolute vertical velocity $-1.975 \pm 1.428 \mathrm{~mm} / \mathrm{yr}$. A likely estimation of the absolute vertical velocity is taken as -2.3475 $\mathrm{mm} / \mathrm{yr}$., an average of the NGL results.

Washington, DC, United States has the nearby GNSS Stations from SONEL of WDC4, of no data, WDC5, of no data, USNO, of absolute vertical velocity $-0.10 \pm 0.19$ $\mathrm{mm} / \mathrm{yr}$;; WDC6, of no data; USN3, of absolute vertical velocity $-0.42 \pm 0.33 \mathrm{~mm} / \mathrm{yr}$.; USN7, of no data, NRL1, of no data, and WDC3, of no data. The closest to the tide gauge from NGL are USNO, of absolute vertical velocity $0.746 \pm 0.675 \mathrm{~mm} / \mathrm{yr}$. and NRL1, of absolute vertical velocity $0.359 \pm 0.882 \mathrm{~mm} / \mathrm{yr}$. The distance to the tide gauge is 5,859 $\mathrm{m}$ for NRL1 and it is $6,380 \mathrm{~m}$ for USNO. A likely estimation of the absolute vertical velocity is taken as $-0.1935 \mathrm{~mm} / \mathrm{yr}$., an average of the NGL results.

Sewells Point, VA, United States has no stations from SONEL. JPL has Smithfield, DRV1, of absolute vertical velocity $-2.393 \pm 1.499 \mathrm{~mm} / \mathrm{yr}$. NGL has also Smithfield, DRV6, of absolute vertical velocity $-2.011 \pm 0.757 \mathrm{~mm} / \mathrm{yr}$. A likely estimation of the absolute vertical velocity is taken as -2.011 $\mathrm{mm} / \mathrm{yr}$., the NGL result for DRV6.

Wilmington, NC, United States has no stations from SONEL. JPL has CASL, of absolute vertical velocity $0.144 \pm 0.74 \mathrm{~mm} / \mathrm{yr}$. NGL has NCWG, of absolute vertical velocity $-2.686 \pm 2.190 \mathrm{~mm} / \mathrm{yr}$. and CASL, of absolute vertical velocity $-0.772 \pm 1.164 \mathrm{~mm} / \mathrm{yr}$. A likely estimation of the absolute vertical velocity is taken as $-1.729 \mathrm{~mm} / \mathrm{yr}$., an average of the NGL results.

Charleston, SC, United States has the nearby GNSS Stations from SONEL of SCCC, absolute vertical velocity $-1.94 \pm 0.28 \mathrm{~mm} / \mathrm{yr}$.; SCHA, of absolute vertical velocity $1.84 \pm 0.64 \mathrm{~mm} / \mathrm{yr}$. and CHA1, of absolute vertical velocity $-1.31 \pm 0.65 \mathrm{~mm} / \mathrm{yr}$. SCHA is the GNSS antenna closest to the tide gauge. The distance to the tide gauge is $200 \mathrm{~m}$. SCCC is also very close, with a distance to the tide gauge of $913 \mathrm{~m}$.
NGL has SCHA, of absolute vertical velocity $-1.098 \pm 0.985$ $\mathrm{mm} / \mathrm{yr}$.; SCCC, of absolute vertical velocity $-1.189 \pm 1.048$ $\mathrm{mm} / \mathrm{yr}$.; CHA1, of absolute vertical velocity $-1.613 \pm 0.980$ $\mathrm{mm} / \mathrm{yr}$. A likely estimation of the absolute vertical velocity is taken as $-1.30 \mathrm{~mm} / \mathrm{yr}$., an average of the NGL results.

Fort Pulaski, GA, United States has the nearby GNSS Station from SONEL of GASK, of signal not robust. The distance to the tide gauge is $12,470 \mathrm{~m}$. NGL has GASK, of absolute vertical velocity $-0.357 \pm 2.167 \mathrm{~mm} / \mathrm{yr}$. A likely estimation of the absolute vertical velocity is taken as -0.357 $\mathrm{mm} / \mathrm{yr}$., the NGL result for GASK.

\subsection{Fernandina Beach, United States}

The MSL trend at Fernandina Beach, FL, United States, Figure 15 , is $+2.11 \mathrm{~mm} /$ year with a $95 \%$ confidence interval of $\pm 0.18 \mathrm{~mm} /$ year, based on MSL data from $1897 / 6$ to $2017 / 12$. The acceleration is $0.01600 \pm 0.01108 \mathrm{~mm} / \mathrm{yr}^{2}$.

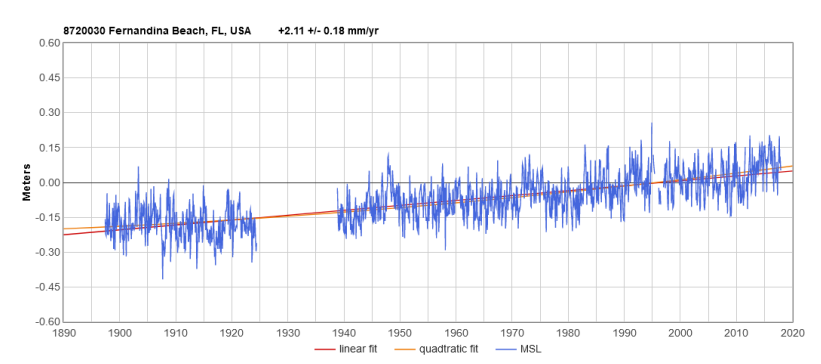

(a)

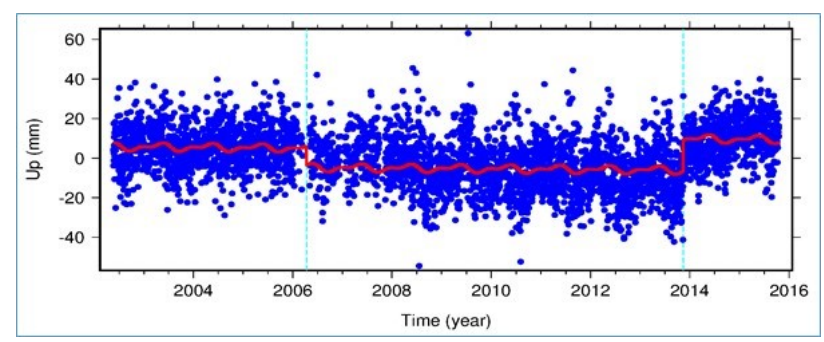

(b)

Figure 15: a) MSL data for Fernandina Beach, FL, United States. Image reproduced modified after [10]; b) GNSS time series for JXVL. Image reproduced modified after [5].

Fernandina Beach, FL, United States has no nearby stations from SONEL. There are no nearby stations also from JPL. Relatively far, NGL has JXVL, of absolute vertical velocity $-0.164 \pm 1.398 \mathrm{~mm} / \mathrm{yr}$. A likely estimation of the absolute vertical velocity is taken as $-0.164 \mathrm{~mm} / \mathrm{yr}$., the NGL result for JXVL. 


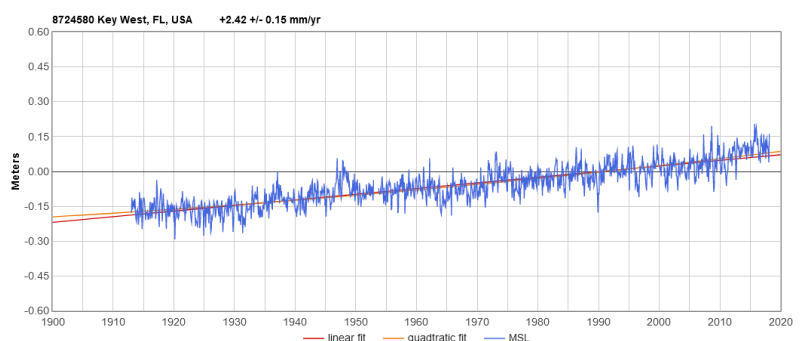

(a)

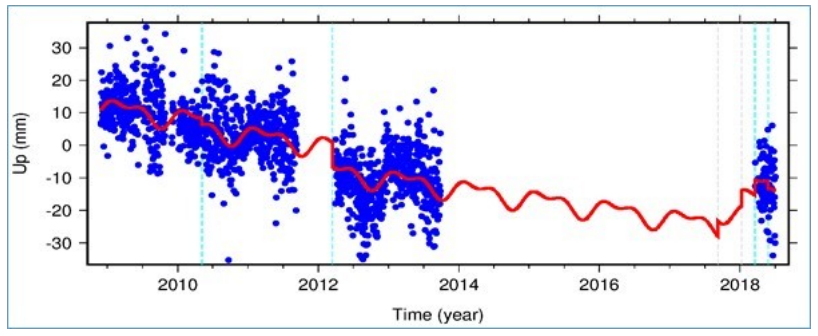

(b)

Figure 16: a) MSL data for Key West, FL, United States. Image reproduced modified after [10]. b) GNSS time series for CHIN. Image reproduced modified after [5].

\subsection{Mayport, United States}

South of Fernandina Beach, the tide gauge record in Mayport is less than 100 years long. The subsidence in Table 1 is obtained as follows.

Mayport, FL, United States has no nearby stations from SONEL. No nearby stations are provided by JPL. Relatively far, NGL has the above mentioned JXVL, of absolute vertical velocity $-0.164 \pm 1.398 \mathrm{~mm} / \mathrm{yr}$. A likely estimation of the absolute vertical velocity is taken as $-0.164 \mathrm{~mm} / \mathrm{yr}$.

\subsection{Key West, United States}

Finally, we reach Key West, the southernmost point of the continental United States. The MSL trend at Key West, FL, United States, Figure 16, is $+2.42 \mathrm{~mm} /$ year with a $95 \%$ confidence interval of $\pm 0.15 \mathrm{~mm} /$ year, based on MSL data from $1913 / 1$ to $2018 / 3$. The acceleration is $0.01412 \pm 0.01064$ $\mathrm{mm} / \mathrm{yr}^{2}$.

Key West, FL, United States has the nearby GNSS Stations from SONEL of KYW5, of absolute vertical velocity $-1.76 \pm 0.43 \mathrm{~mm} / \mathrm{yr}$.; KWST, of absolute vertical velocity $-1.07 \pm 0.38 \mathrm{~mm} / \mathrm{yr}$; KYW1, of absolute vertical velocity $0.26 \pm 0.43 \mathrm{~mm} / \mathrm{yr}$. ; and CHIN, of signal not robust. CHIN is the GNSS antenna closest to the tide gauge, with a distance to the tide gauge of $400 \mathrm{~m}$, then KWST is the closest, with a distance to the tide gauge of 5,424 m. NGL has KYW1, of absolute vertical velocity $-0.167 \pm 0.822 \mathrm{~mm} / \mathrm{yr}$.; KYW2, of ab- solute vertical velocity $0.014 \pm 0.982 \mathrm{~mm} / \mathrm{yr}$.; KYW5, of absolute vertical velocity $-0.153 \pm 1.081 \mathrm{~mm} / \mathrm{yr}$.; KYW6, of absolute vertical velocity $0.044 \pm 1.208 \mathrm{~mm} / \mathrm{yr}$; CHIN, of absolute vertical velocity $-2.916 \pm 2.278 \mathrm{~mm} / \mathrm{yr}$.; KWST, of absolute vertical velocity $-1.489 \pm 0.834 \mathrm{~mm} / \mathrm{yr}$. The NGL result for CHIN of $-2.916 \mathrm{~mm} / \mathrm{yr}$. is taken as a likely estimation of the absolute vertical velocity.

\section{Discussion}

In the 33 LTT stations along the East Coast of North America, the average relative rate of rise is $2.22 \mathrm{~mm} / \mathrm{yr}$. subjected to a small, positive acceleration of $+0.0027 \mathrm{~mm} / \mathrm{yr}^{2}$. The average relative rate of rise of the 11 stations in Canada is $0.61 \mathrm{~mm} / \mathrm{yr}$. subjected to a negative acceleration of -0.0133 $\mathrm{mm} / \mathrm{yr}^{2}$ while theaverage relative rate of rise of the $22 \mathrm{sta}$ tions of the United States is $3.02 \mathrm{~mm} / \mathrm{yr}$. subjected to a positive acceleration of $+0.0108 \mathrm{~mm} / \mathrm{yr}^{2}$. Excessive groundwater withdrawal-induced subsidence is much stronger for the East coast of the United States than Canada,

The acceleration result is consistent with other global and regional estimations from LTT stations such as [25] to [28] recently reported as the latest average acceleration of worldwide data sets is still very close to zero. The Mitrovica's 23 gold standard tide stations with minimal vertical land motion have average acceleration $+0.0020 \pm 0.0173$ $\mathrm{mm} / \mathrm{yr}^{2}$. The Holgate's nine excellent tide gauge records of sea-level measurements have average acceleration $+0.0029 \pm 0.0118 \mathrm{~mm} / \mathrm{yr}^{2}$. The NOAA’s 42 U.S. long term trend tide stations of 2011 have average acceleration $+0.0025 \pm 0.0308 \mathrm{~mm} / \mathrm{yr}^{2}$. The California-8 long term trend tide stations have average acceleration $+0.0014 \pm 0.0266$ $\mathrm{mm} / \mathrm{yr}^{2}$. The LTT stations of the East Coast of North America have acceleration values on average positive, but of the order of the nanometers per year squared, similarly to the other data sets.

In addition to Table 1, also Figure 17 presents a summary of the sea level and GNSS results for the LTT stations of the East coast of North America. $\boldsymbol{u}$ is the relative sealevel rise, $\boldsymbol{w}$ is the absolute vertical velocity at the GNSS antenna nearby the tide gauge, and $\boldsymbol{v}=\boldsymbol{u}+\boldsymbol{w}$ is the absolute sea-level rise.

In the 11 stations of Canada, of average relative sealevel rise $0.61 \mathrm{~mm} / \mathrm{yr}$., the average absolute velocity of the tide gauge instrument as guessed from the GNSS data is $0.43 \mathrm{~mm} / \mathrm{yr}$. translating in an absolute sea-level rise of $+1.04 \mathrm{~mm} / \mathrm{yr}$. The average absolute velocity of the tide gauge instrument from GIA VM2 and VM4 is $0.02 \mathrm{~mm} / \mathrm{yr}$. 
and $-0.16 \mathrm{~mm} / \mathrm{yr}$. respectively. The absolute rate of rise of the sea level from GIA VM2 is $0.63 \mathrm{~mm} / \mathrm{yr}$.

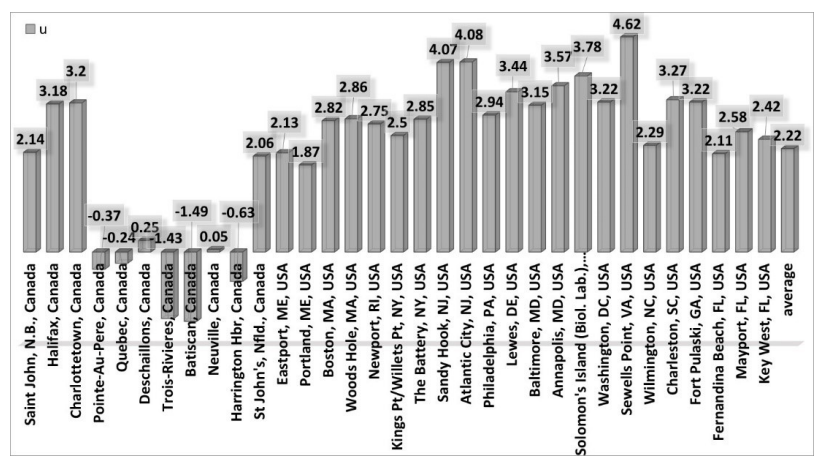

(a)

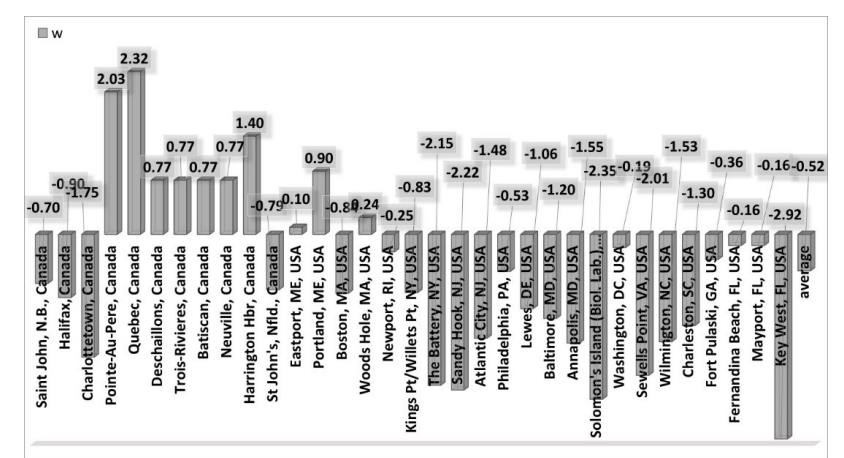

(b)

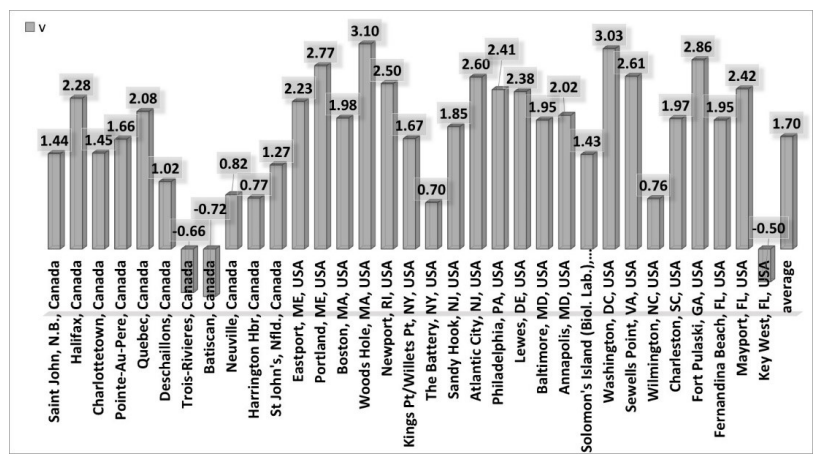

(c)

Figure 17: Summary of sea-level rise and subsidence results. $\boldsymbol{u}$ is the relative sea-level rise, $\boldsymbol{w}$ is the absolute vertical velocity at the GNSS antenna nearby the tide gauge, and $\boldsymbol{v}=\boldsymbol{u}+\boldsymbol{w}$ is the absolute sea-level rise. Units are $\mathrm{mm} / \mathrm{yr}$.

In the 22 stations of the US, of average relative sealevel rise $3.02 \mathrm{~mm} / \mathrm{yr}$., the average absolute velocity of the tide gauge instrument as guessed from the GNSS data is $0.96 \mathrm{~mm} / \mathrm{yr}$. translating in an absolute sea-level rise of 2.06 $\mathrm{mm} / \mathrm{yr}$. The average absolute velocity of the tide gauge instrument from GIA VM2 and VM4 is $-1.15 \mathrm{~mm} / \mathrm{yr}$. and -0.42

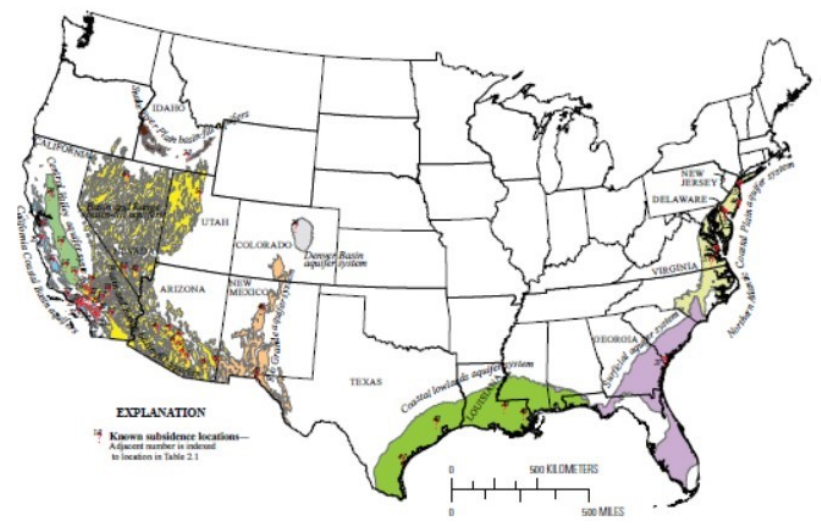

Figure 18: Selected, known areas of land subsidence, owing primarily or secondarily to groundwater or oil and gas abstractions, in the 48 conterminous United States, and associated aquifer systems. Image reproduced modified from [29].

$\mathrm{mm} / \mathrm{yr}$. respectively. The absolute rate of rise of the sea level from GIA VM2 is $1.88 \mathrm{~mm} / \mathrm{yr}$.

In all the 33 stations, of average relative sea-level rise $2.22 \mathrm{~mm} / \mathrm{yr}$, the average absolute velocity of the tide gauge instrument as guessed from the GNSS data is $-0.50 \mathrm{~mm} / \mathrm{yr}$. translating in an absolute sea-level rise of $1.72 \mathrm{~mm} / \mathrm{yr}$. The average absolute velocity of the tide gauge instrument from GIA VM2 and VM4 is $-0.76 \mathrm{~mm} / \mathrm{yr}$. and $-0.33 \mathrm{~mm} / \mathrm{yr}$. respectively. The absolute rate of rise of the sea level from GIA VM2 is $1.46 \mathrm{~mm} / \mathrm{yr}$.

The subsidence along the East Coast of the United States is very well-known [14, 29, 30]. Hence, it should not be a surprise if along the East Coast of the United States the relative rates of rise of the sea level are generally higher than along the West Coast of the United States, where apart from southern California, subsidence is less relevant.

\section{Conclusions}

The GNSS monitoring of the position of antennas, is superior to GIA model computations, to assess vertical land velocities in general, and vertical movements of tide gauge instruments in particular. However, the technique still suffers from major uncertainties, as demonstrated by the differences between the estimates from different providers for the same antennas that are often larger than the trend. The measurements at the tide gauges are the best way to understand sea-level changes. These measurements show a stable pattern of mild rising sea levels with negligible accelerations mostly explained by the sinking of the tide gauge instrument. 
In the 33 LTT stations along the East Coast of North America, the average relative rate of rise is $2.22 \mathrm{~mm} / \mathrm{yr}$. subjected to a small, positive acceleration of +0.0028 $\mathrm{mm} / \mathrm{yr}^{2}$. The average relative rate of rise of the 11 stations in Canada is $0.61 \mathrm{~mm} / \mathrm{yr}$. subjected to a negative acceleration of $-0.0133 \mathrm{~mm} / \mathrm{yr}^{2}$. The average relative rate of rise of the 22 stations of the United States is $3.02 \mathrm{~mm} / \mathrm{yr}$. subjected to a positive acceleration of $+0.0108 \mathrm{~mm} / \mathrm{yr}^{2}$. The average absolute velocity of the 33 tide gauge instruments from the GNSS data is $-0.52 \mathrm{~mm} / \mathrm{yr}$. The average absolute sea-level rise is $1.70 \mathrm{~mm} / \mathrm{yr}$. The average absolute velocity of the 33 tide gauge instruments from GIA VM2 and VM4 is $-0.76 \mathrm{~mm} / \mathrm{yr}$. and $-0.33 \mathrm{~mm} / \mathrm{yr}$. respectively translating in averages absolute sea-level rise of $1.46 \mathrm{~mm} / \mathrm{yr}$. and 1.89 $\mathrm{mm} / \mathrm{yr}$. from GIA VM2 and VM4, respectively.

The result here obtained is compatible with a global temperature recovery from the low temperatures of the Little Ice Age (LIA) plus the effect of subsidence. This paper adds to the many contributions, such as [25] to [28], [31] to [79] that demonstrate the world sea levels are rising slowly and with only a small acceleration component.

Acknowledgment: The author received no funding.

Conflict of interest: The author declares no conflict of interest regarding the publication of this paper.

\section{References}

[1] Peltier WR. Global glacial isostatic adjustment and modern instrumental records of relative sea-level history. Int Geophysics. 2001;75:65-95.

[2] Wöppelmann G, Letetrel C, Santamaria A, Bouin MN, Collilieux $X$, Altamimi Z, et al. Rates of sea-level change over the past century in a geocentric reference frame. Geophys Res Lett. 2009;36(12):L12607. https://doi.org/10.1029/2009GL038720.

[3] Système d'Observation du Niveau des Eaux Littorales (SONEL). www.sonel.org

[4] National Aeronautics and Space Administration (NASA) Jet Propulsion Laboratory. (JPL). sideshow.jpl.nasa.gov/post/series.html

[5] Nevada Geodetic Lab (NGL). geodesy.unr.edu

[6] Blewitt G, Kreemer C, Hammond WC, Gazeaux J. MIDAS robust trend estimator for accurate GPS station velocities without step detection. J Geophys Res Solid Earth. 2016 Mar;121(3):2054-68.

[7] Permanent Service for Mean Sea Level (PSMSL). www.psmsl.org

[8] Schlesinger M, Ramankutty N. An oscillation in the global climate system of period 65-70 years. Nature. 1994;367(6465):723-6.

[9] Chambers, D, Merrifield MA, Nerem RS. Is there a 60-year oscillation in global mean sea level?, Geophys. Res. Lett..
2012; 39(18); 2012GL052885.

[10] sealevel.info. www.sealevel.info

[11] National Oceanic and Atmospheric Administration. (NOAA, tidesandcurrents.noaa.gov)

[12] Peltier WR. Postglacial Variations in the Level of the Sea: Implications for Climate Dynamics and Solid-Earth Geophysics. Rev Geophys. 1998;36(4):603-89.

[13] Peltier WR. Global Glacial Isostasy and the Surface of the IceAge Earth: the ICE-5G(VM2) model and GRACE. Annu Rev Earth Planet Sci. 2004;32(1):111-49.

[14] Galloway DL, Jones DR, Ingebritsen SE. Land subsidence in the United States. United States Geological Survey. 1999; 1182. pubs.usgs.gov/circ/circ1182/

[15] National Research Council. Mitigating losses from land subsidence in the United States. Washington: D. C., National Academy Press. 1991; 58.

[16] Johnson DW. Is the Atlantic Coast Sinking? Geogr Rev. 1917;3(2):135-9.

[17] Davis GH. Land subsidence and sea level rise on the Atlantic Coastal Plain of the United States. Environ Geol Water Sci. 1987;10(2):67-80.

[18] United States Geological Survey. Land Subsidence in the United States, United States Geological Survey Fact Sheet087-00, 2000. water.usgs.gov/ogw/gwrp/fs2001/test1/

[19] Karegar MA, Dixon TH, Engelhart SE. Subsidence along the Atlantic Coast of North America: insights from GPS and late Holocene relative sea level data. Geophys Res Lett. 2016;43(7):3126-33.

[20] Mörner NA, Klein PM. The Fiji tide-gauge stations. Int J Geosci. 2017;8(04):536-44.

[21] Mörner NA. Glacial Isostasy: Regional-Not Global. Int J Geosci. 2015;6(06):577-92.

[22] www.sealevel.info/resources.html\#peltier

[23] www.psmsl.org/train_and_info/geo_signals/gia/peltier/

[24] www.psmsl.org/train_and_info/geo_signals/gia/peltier/drsl. PSMSL.ICE5G_VM4_L90.txt

[25] Houston JR, Dean RG. Sea-Level Acceleration Based on U.S. Tide Gauges and Extensions of Previous Global-Gauge Analyses. J Coast Res. 2011;27(3):409-17.

[26] Parker A. Sea level trends at locations of the United States with more than 100 years of recording. Nat Hazards. 2013;65(1):1011-21.

[27] Parker A, Ollier CD. California sea level rise: evidence based forecasts vs. model predictions. Ocean Coast Manage. 2017;149:198-209.

[28] Parker A, Ollier CD. Short-Term Tide Gauge Records from One Location are Inadequate to Infer Global Sea-Level Acceleration. Earth Systems and Environment. 2017;1(2):17.

[29] Galloway DL, Bawden GW, Leake SA, Honegger DG. Land subsidence hazards, inBaum, R. L., Galloway, D.L., Harp, E.L., (eds), Landslide and land subsidence hazards to pipelines: U.S. Geological Survey Open-File Report 2008-1164, chapter 2, 2008. pubs.usgs.gov/of/2008/1164/

[30] Galloway DL, Sneed M. Analysis and simulation of regional subsidence accompanying groundwater abstraction and compaction of susceptible aquifer systems in the USA. Bol Soc Geol Mex. 2013;65(1):123-36.

[31] Beenstock M, Reingewertz Y, Paldor N. Polynomial cointegration tests of anthropogenic impact on global warming. Earth Syst Dyn. 2012;3(2):173-88. 
[32] Beenstock M, Felsenstein D, Frank E, Reingewertz Y. Tide gauge location and the measurement of global sea level rise. Environ Ecol Stat. 2015;22(1):179-206.

[33] Boretti A. Is there any support in the long term tide gauge data to the claims that parts of Sydney will be swamped by rising sea levels? Coast Eng. 2012;64:161-7.

[34] Boretti A. Short Term Comparison of Climate Model Predictions and Satellite Altimeter Measurements of Sea Levels. Coast Eng. 2012;60:319-22.

[35] Boretti A, Watson T. The inconvenient truth: ocean Levels are not accelerating in Australia. Energy Environ. 2012;23(5):80117.

[36] Dean RG, Houston JR. Recent sea level trends and accelerations: comparison of tide gauge and satellite results. Coast Eng. 2013;75:4-9.

[37] Douglas B. Global Sea Level Acceleration, J. Geophysical Research. 1992;97(8);12: 699-12, 706. https://doi.org/10.1029/92JC01133.

[38] Douglas B, Peltier WR. The Puzzle of Global Sea-Level Rise. Phys Today. 2002;55(3):35-40.

[39] Holgate SJ. On the decadal rates of sea level change during the twentieth century. Geophys Res Lett. 2007;34(1):L01602. https://doi.org/10.1029/2006GL028492.

[40] Jevrejeva S, Grinsted A, Moore JC, Holgate S. Nonlinear trends and multiyear cycles in sea level records. J Geophys Res Oceans. 2006;111 C9.

[41] Jevrejeva S, Moore JC, Grinsted A, Woodworth P. Recent global sea level acceleration started over 200 years ago? Geophys Res Lett. 2008;35(8):L08715.https://doi.org/10.1029/2008GL033611.

[42] Mörner NA. Estimating future sea level changes. Global Planet Change. 2004;40(1-2):49-54.

[43] Mörner NA. Sea Level Changes and Tsunamis, Environmental Stress and Migration over the Seas. Int Asienforum. 2007;38:353-74.

[44] Mörner NA. Sea level changes in Bangladesh new observational facts. Energy Environ. 2010;21(3):235-49.

[45] Mörner NA. Some problems in the reconstruction of mean sea level and its changes with time. Quat Int. 2010;221(1-2):3-8.

[46] Mörner NA. There Is No Alarming Sea Level Rise! 21st Century Science and Technology, Fall. 2010;7-17.

[47] Mörner NA. Setting the frames of expected future sea level changes by exploring past geological sea level records, Chapter 6 of book, D Easterbrook, Evidence-Based Climate Science. 2011.

[48] Mörner NA. The Maldives: A measure of sea level changes and sea level ethics, Chapter 7 of book, D Easterbrook, EvidenceBased Climate Science. 2011.

[49] Mörner NA. Sea level changes past records and future expectations. Energy Environ. 2013;24(3-4):509-36.

[50] Mörner NA. Rates of Sea Level Changes-A Clarifying Note, by Nils-Axel Mörner. Int J Geosci. 2016;7(11):1318-22.

[51] Morner NA. Chapter 12 - Sea Level Changes as Observed in Nature, in Evidence-Based Climate Science (Second Edition), Data Opposing CO2 Emissions as the Primary Source of Global Warming. 2016; 215-229.

[52] Okunaka Y, Hirahara T. Long-term trend of sea level on coast of Japan - Recent research review and correction using ground variation by GPS observation. Sokkou-jiho. 2016;83:S21.
[53] Ollier C. Sea Level in the Southwest Pacific is stable. Energy Environ. 2010;21(7):833-9.

[54] Parker A. Oscillations of sea level rise along the Atlantic coast of North America north of Cape Hatteras. Nat Hazards. 2013;65(1):991-7.

[55] Parker A. Lower Bounds to Future Sea-Level Rise. International Journal of Ocean and Climate Systems. 2013;4(3):197-211.

[56] Parker A. Natural oscillations and trends in long-term tide gauge records from the Pacific. Pattern Recogn. Phys. 2013;1(1):1-13.

[57] Parker A. Apparent hot and cold spots of acceleration along the Atlantic and Pacific coasts of the United States. Nonlinear Eng. 2014;3(1):51-6.

[58] Parker A. Impacts of sea level rise on coastal planning in Norway. Ocean Eng. 2014;78:124-30.

[59] Parker A. Minimum 60 years of recording are needed to compute the sea level rate of rise in the Western South Pacific. Nonlinear Eng. 2014;3(1):1-10.

[60] Parker A. The Sea Level Rate of Rise and the Subsidence Rate Are Constant in Fremantle, American Journal of Geophysics. Geochemistry and Geosystems. 2016;2(4):43-50.

[61] Parker A. Rates of subsidence and relative sea level rise in the Hawaii Islands. Nonlinear Eng. 2016;5(4):255-68.

[62] Parker A. Coldspot of Decelerated Sea-Level Rise on the Pacific Coast of North America. Quaest Geogr. 2016;35(3):31-7.

[63] Parker A. Atlantic Meridional Overturning Circulation is stable under global warming. Proc Natl Acad Sci USA. 2016 May;113(20):E2760-1. =

[64] Parker A. Analysis of the sea levels in Kiribati a rising sea of misrepresentation sinks Kiribati. Nonlinear Eng. 2016;5(1):3743.

[65] Parker A. The actual measurements at the tide gauges do not support strongly accelerating twentieth-century sea-level rise reconstructions. Nonlinear Eng. 2016;5(1):45-71.

[66] Parker A. There Is no Indication That the Extreme Water Levels in Rhode Island have Strongly Accelerated Since the Start of the 20th Century. American Journal of Environment and Sustainable Development. 2017;2(4):37-42.

[67] Parker A. Sea level oscillations in Japan and China since the start of the 20th century and consequences for coastal management - Part 2: china pearl river delta region. Ocean Coast Manage. 2018;163(1):456-65.

[68] Parker A. Absolute rates of sea level rise based on Tide Gauges and Global Navigation Satellite System Along the West Coast of North America. Nonlinear Eng. Forthcoming 2020.

[69] Parker A. Tide gauge of absolute sea level rise negative removed from data base. New Concepts in Global Tectonics Journal. 2018;6(2):314-6.

[70] Parker A. TUVALU SEA LEVEL RISE, LAND CHANGE, MISMANAGEMENT AND OVERPOPULATION. New Concepts in Global Tectonics Journal. 2018;6(1):107-23.

[71] Parker A. Sea level oscillations in Japan and China since the start of the 20th century and consequences for coastal management-Part 1: Japan. Ocean Coast Manage. 2019;169:225-38.

[72] Parker A, Ollier CD. Coastal planning should be based on proven sea level data. Ocean Coast Manage. 2015;124:1-9.

[73] Parker A, Ollier CD. IS THE SEA LEVEL STABLE AT ADEN, YEMEN? Earth Syst. Environ. 2017;1(2):18. 
[74] Parker A, Ollier C. Pacific sea levels rising very slowly and not accelerating. Quaest Geogr. 2019;38(1):179-84.

[75] Scafetta N. Multi-scale dynamical analysis (MSDA) of sea level records versus PDO, AMO, and NAO indexes. Clim Dyn. 2014;43(1-2):175-92.

[76] Schmith T, Johansen S, Thejll P. Statistical analysis of global surface temperature and sea level using cointegration methods. J Clim. 2012;25(22):7822-33.

[77] Wunsch R, Ponte R, Heimbach P. Decadal trends in sea level patterns: 1993-2004. J Climatol. 2007;20(24):5889-911.

[78] Wenzel M, Schröter J. Reconstruction of regional mean sea level anomalies from tide gauges using neural networks. J Geophys Res Oceans. 2010;115:C08013.

[79] Boretti A. Absolute and relative sea-level rise in the New York City area by measurements from tide gauges and satellite global positioning system, J Ocean Eng Sci. 2020, doi.org/https://doi.org/10.1016/j.joes.2020.05.001 